\title{
Barreira pandêmica à acessibilidade: do direito ao medo na cidade contemporânea
}

\section{The pandemic barrier against accessibility: from rights to fear in contemporary cities}

\section{La barrera pandémica contra la accesibilidad: de los derechos al miedo en las ciudades contemporáneas}

Eduardo Patricio da Silva, mestre em Estudos Urbanos e Regionais pela Universidade Federal do Rio Grande do Norte. Doutorando em Arquitetura e Urbanismo (Área de Concentração: Cidades) pela Universidade Federal de Alagoas.

E-mail: heroidedeus@hotmail.comＤORCID: https://orcid.org/0000-0003-1080-0186

Morgana Maria Pitta Duarte Cavalcante, doutora em Arquitetura e Urbanismo pela Universidade Presbiteriana Mackenzie. Professora titular do Programa de PósGraduação em Arquitetura e Urbanismo da Universidade Federal de Alagoas. E-mail: morgana.duarte@fau.ufal.br (D)ORCID: https://orcid.org/0000-0003-0975-2412

Thaisa Sampaio Sarmento, doutora em Design pela Universidade Federal de Pernambuco. Professora titular do Programa de Pós-Graduação em Arquitetura e Urbanismo da Universidade Federal de Alagoas.

E-mail: thaisa.sampaio@fau.ufal.br DORCID: https://orcid.org/0000-0002-5460-1392

Para citar este artigo: SILVA, E. P.; CAVALCANTE, M. M. P.; SARMENTO, T. S. Barreira Pandêmica à acessibilidade: do direito ao medo na cidade contemporânea. Cadernos de Pós-Graduação em Arquitetura e Urbanismo, São Paulo, v. 22, n.1, p. 85-99, 2022. DOI 10.5935/cadernospos.v22n1p85-99

Submissão: 2021-03-26

Aceite: $2021-09-20$ 


\section{Resumo}

Este artigo discute como a apropriação dos espaços da cidade tem sido modificada com a pandemia da Covid-19, estendendo a discussão das barreiras à acessibilidade para questões de segurança sanitária. É apresentado um panorama brasileiro de como a pessoa com deficiência está inserida nas dinâmicas da vida urbana e em relação ao período de proliferação da pandemia de Covid-19. A base teórica é apoiada nos textos de Bauman (2009), Lefebvre (2001), Jacobs (2011), Gehl (2015), Castells (2020), Agamben et al. (2020) e Morin (2020). As discussões apontaram para formas crescentes de exclusão social em relação às diferentes apresentações das deficiências nas camadas sociais da população brasileira. A pandemia agravou problemas urbanos anteriores, explicitando a crise de segurança sanitária no Brasil e a falta de acessibilidade à informação consistente por parte dessas pessoas para sua proteção e prevenção à doença. Diante das incertezas que permeiam a atualidade, o futuro pós-pandêmico ainda não se apresenta como cenário promissor. Resta-nos a esperança da mudança para melhores condições de segurança sanitária, de acesso à informação e de uma nova mentalidade voltada às políticas de assistência à pessoa com deficiência, voltadas à inclusão social e urbana.

Palavras-chave: Covid-19; Medo da cidade; Pessoa com deficiência; Reconfinamento; Barreira pandêmica à acessibilidade.

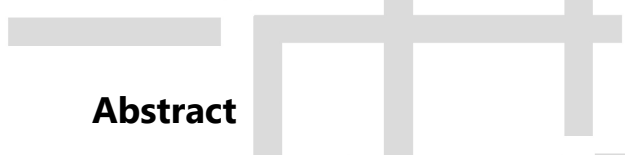

This paper discusses how the appropriation of city spaces has been changed with the Covid19 pandemic, extending the discussions about barriers to accessibility to the issues of health safety. Therefore, is presented a Brazilian overview that show how the disabled person is inserted in the dynamics of urban life and in the period of proliferation of the covid-19 pandemic. The theoretical basis is supported by the texts of Bauman (2009), Lefebvre (2001), Jacobs (2011), Gehl (2015), Castells (2020), Agamben et al. (2020) and Morin (2020). The discussions pointed to growing forms of social exclusion in relation to the different presentations of disabilities in the social strata of the Brazilian population. The pandemic aggravated previous urban problems, making explicit the health security crisis in Brazil and the lack of accessibility to consistent information by these people for their protection and prevention of the disease. In the face of the uncertainties that permeate today, the postpandemic future does not yet present itself as a promising scenario. We are left with the hope of change for better health security conditions, access to information, and a new mentality focused on policies that assist people with disabilities, that aimed their social and urban inclusion.

Keywords: Covid-19; Fear of the city; Person with disabilities; Reconfinement; Pandemic barrier to accessibility.

\section{Resumen}

Este artículo analiza cómo se ha modificado la apropiación de los espacios de la ciudad con la pandemia de Covid-19, ampliando los debates sobre las barreras a la accesibilidad a las cuestiones de seguridad sanitaria. Por lo tanto, se presenta un panorama brasileño que muestra cómo la persona con discapacidad se inserta en la dinámica de la vida urbana y en el período de proliferación de la pandemia del covid-19. La base teórica se apoya en los textos de Bauman (2009), Lefebvre (2001), Jacobs (2011), Gehl (2015), Castells (2020), 
Agamben et al. (2020) y Morin (2020). Los debates señalaron las crecientes formas de exclusión social en relación con las diferentes presentaciones de las discapacidades en los estratos sociales de la población brasileña. La pandemia agravó los problemas urbanos anteriores, haciendo explícita la crisis de seguridad sanitaria en Brasil y la falta de accesibilidad a información consistente por parte de estas personas para su protección y prevención de la enfermedad. Frente a las incertidumbres que impregnan la actualidad, el futuro post-pandémico no se presenta aún como un escenario prometedor. Nos queda la esperanza de cambio para mejores condiciones de seguridad sanitaria, el acceso a la información y una nueva mentalidad centrada en las políticas de ayuda a las personas con discapacidad, que apuntan a su inclusión social y urbana.

Palabras clave: Covid-19; Miedo a la ciudad; Persona con discapacidad; Reconfinamiento; Barrera pandémica a la accesibilidad. 


\section{INTRODUÇÃO}

A

valorização da apropriação dos espaços da cidade e das interações humanas nestes, como forma de efetivação de uma vida urbana plena e saudável em suas dimensões, foi amplamente defendida por autores que tratam do tema cidade, como Henri Lefebvre (2001), Jane Jacobs (2011), Zygmunt Bauman (2009), Jan Gehl (2015), dentre outros. No entanto, com a pandemia de Covid-19, essas discussões ganharam novos pontos de vista.

Os espaços da cidade, imprescindíveis para a interação social e para a vida urbana em plena dinâmica, agora assumem diversos status de locais de infecção - de plataformas das manifestações da vida para potenciais ambientes facilitadores da doença - de desejáveis para inadequados - de locais de permanência e interação humana para, no muito, locais de circulação em extrema necessidade.

Em paralelo a essa vertiginosa mudança no modo de viver em cidades contemporâneas, as pessoas com deficiência enfrentam a ampliação das barreiras à acessibilidade urbana - desde as "clássicas", como as atitudinais e físicas, a algo bem mais abstrato, como o medo da infecção e da morte. Isso em duas perspectivas: o medo que a pessoa com deficiência tem de ser infectada pela Covid-19, por integrar o grupo de risco, e, o que os demais possuem de se infectar ao tocarem os corpos ou equipamentos ortopédicos daqueles que necessitam de suporte ou apoio para acessarem diversos espaços e equipamentos urbanos.

Na construção histórico-social acerca da pessoa com deficiência e suas reverberações na configuração do desenho urbano das cidades brasileiras, evidenciadas nas diversas barreiras à acessibilidade presentes nestas, ocorreram nas últimas décadas avanços institucionais e legais no país, como as publicações das leis no 10.048/2000 (BRASIL, 2000) e $n^{\circ}$ 10.098/2000 (BRASIL. 2000), que estabelecem normas gerais e critérios básicos para a promoção da acessibilidade;o Decreto no 5.296/2004 (BRASIL, 2004), que as regulamenta, e a criação do Estatuto da Pessoa com Deficiência (Lei $n^{\circ}$ 13.146/2015) (BRASIL, 2015), dentre outras.

Entretanto, a realidade pandêmica da Covid-19 trouxe um retrocesso nas ações de redução das desigualdades sociais. O confinamento para essas pessoas ocorreu de forma mais intensa e brutal, na medida em que receber qualquer auxílio dentro ou fora de casa se tornou um risco iminente de contágio, ou, ainda, receber informação adequada às suas condições de compreensão e mudança de atitudes cotidianas podem não ter sido feitas com rapidez necessária. Além de a busca por atendimento de saúde possivelmente ter sofrido maior agravamento e dificuldades, desde solicitação de atendimento, passando pelo deslocamento físico até o ponto de atendimento e as relações sociais para receber atendimento.

Esse novo inimigo invisível, personificado pelo já mencionado medo bilateral de infecção, gerou desde a ampliação do confinamento atual das pessoas com deficiência, até o reconfinamento das tais, causando, assim, um retrocesso nos avanços que dizem respeito à inclusão desses indivíduos nos espaços da cidade. 
Este artigo objetiva apresentar uma breve descrição do quadro de inserção urbana da pessoa com deficiência antes e após o advento da pandemia de Covid-19, por meio de um levantamento bibliográfico e da coleta de alguns depoimentos desses sujeitos sociais, trazendo, ainda, uma crítica aos atuais determinismos acerca do futuro póspandêmico que tratam dos novos modos de apropriação e uso dos espaços da cidade.

\section{A cidade pré-pandêmica e a pessoa com deficiência}

Para Bauman (2009), os espaços da cidade são os locais onde a vida urbana atinge a sua mais completa expressão, nos quais descobrimos, aprendemos e acima de tudo praticamos as maneiras e costumes de uma convivência satisfatória. $O$ autor propõe que isso só é possível quando a configuração dos espaços da cidade é inclusiva e valoriza a diversidade dos indivíduos.

Enquanto locais de interação humana, Lefebvre (2001) defende que o direito à cidade só pode ser formulado como o direito à vida urbana renovada e transformada em um viver a cidade mais pleno, divertido e menos alienante. Segundo o teórico, a democratização do uso desses espaços constitui, portanto, papel preponderante.

Por sua vez, Jacobs (2011) criticou a lógica do urbanismo moderno do ano de 1961, que priorizava a construção de viadutos, elevados e vias expressas que privilegiavam o uso de automóveis em detrimento dos espaços urbanos como locais de permanência e de encontro. o autor defende o uso das calçadas e dos espaços públicos como locais propícios para a construção e fortalecimento das relações humanas e do sentimento de pertencimento à cidade.

Gehl (2015) também critica a desconsideração de aspectos qualitativos da cidade e dos seus espaços por parte dos planejadores urbanos modernistas na década de 1960, o que, segundo o mesmo, excluiu a valorização do caminhar e do encontrar pessoas nos espaços urbanos comuns. Visão essa que se estendeu para as décadas posteriores, norteando, assim, o novo desenvolvimento urbano ao redor do mundo. $\mathrm{O}$ autor ainda acrescenta que, ao longo dos anos, a dimensão humana tem sido um tópico esquecido no planejamento urbano, sendo substituído pela ênfase na acomodação do vertiginoso aumento do tráfego de automóveis, o que gera baixa prioridade ao espaço público, às áreas destinadas aos pedestres e ao importante papel do espaço urbano como local de encontro e permanência dos habitantes da cidade.

Segundo Garcia (2012), a maioria das cidades contemporâneas possui desenhos urbanos que remontam às proposições da Carta de Atenas de 1933, na qual a cidade deveria ser organizada de maneira funcional, sendo cada função urbana distribuída, espacialmente, em zonas previamente determinadas: 1) de habitar; 2) de trabalhar; 3) de lazer e recreação; e 4) de circular. A mesma ressalta que esses zoneamentos da cidade acabaram privilegiando o uso de veículos motorizados em virtude das longas distâncias entre tais zonas, o que acabou prejudicando principalmente os deslocamentos urbanos das pessoas com deficiência ou mobilidade reduzida.

Maricato (2015) define essa ênfase dos projetos urbanos das cidades brasileiras como império do automóvel, o que, de acordo com esta, fez com que as condições de mobilidade no país se tornassem um de seus maiores problemas sociais e urbanos, 
causando desde sérios danos à saúde populacional e ao meio ambiente, até o aumento consideravelmente dos índices de violência no trânsito.

Tais autores valorizam a apropriação dos espaços urbanos como forma de efetivação do direito à cidade, apesar de reconhecerem que esta também é palco de diversas contradições, como a desconsideração do fator humano em suas configurações; algo que se expressa na consequente segregação urbana imposta àqueles que possuem restrições físicas de mobilidade.

Essa desconsideração das pessoas com deficiência nas idealizações dos espaços, no entanto, não é aleatória nem recente; remonta, aliás, a uma longa construção históricosocial, trazida para o Brasil com a colonização portuguesa, e o modo de viver das famílias daquela época, que já restringiam o acesso à educação e ao convívio social a seus filhos que traziam alguma má formação física ou cognitiva.

Apesar de a legislação brasileira de acessibilidade ser considerada uma das mais avançadas do mundo e, dos já citados autores que tratam do tema "cidade" considerarem os espaços desta os locais onde a vida urbana se desdobra em sua mais completa expressão social de igualdade - possibilitando o nosso convívio com os ambientes, com a natureza e com as pessoas; isso, porém, não se estende a todos.

Existem, por outro lado, aqueles que são segregados, repelidos e excluídos por esses mesmos espaços, pelo simples fato de não disporem da plenitude física necessária para transpor as diversas barreiras neles presentes, impostas por um modelo de cidade que desconsiderou suas existências, restando à maioria dos tais o confinamento e a consequente negação do direito à cidade.

\section{Covid-19: uma nova barreira invisível}

Conforme exposto, as cidades brasileiras estão repletas de barreiras à acessibilidade, o que faz com que pessoas com deficiência ou mobilidade reduzida tenham geralmente o seu direito constitucional de ir e vir negado. Apesar dessa realidade, esses indivíduos possuem uma segurança jurídica que foi conquistada por diversos movimentos sociais e urbanos ao longo das últimas décadas, possibilitando-lhes certo grau de cumprimento do seu direito à cidade, mesmo que quando reivindicado. Porém, a Covid-19 pôs e ainda põe em discussão uma nova barreira à acessibilidade: a segurança sanitária.

Por muitos anos, o fenômeno da autosegregação espacial foi fruto da mixofobia - isto é, do medo de se misturar com o outro - fosse com o estrangeiro ou com o diferente, constituindo, assim, a busca pelo fortalecimento da relação conosco ao invés de com o outro, convergindo em grupos de indivíduos com maior grau possível de homogeneidade social.

Esse movimento gerou um forte impulso em direção a ilhas de identidade e de semelhança com esses iguais. Essa autosegregação espacial foi desencadeada basicamente pelo medo dos potenciais (ou imaginários) riscos oriundos da múltipla diversidade urbana, gerando severas fragmentações sociais entre as pessoas da primeira fila (moradores de condomínios fechados) e as da última fila (demais cidadãos), divisão onde os primeiros não se identificam nem se interessam com as 
localidades próximas externas aos seus enclaves fortificados. Algo que se caracteriza nitidamente como uma negação da cidade, com indivíduos habitando, em paralelo, nas suas moradas virtuais, ou seja, no ciberespaço (BAUMAN, 2009).

No cenário pandêmico atual, esse medo do outro foi substituído pelo medo da infecção e da respectiva morte, onde os governos municipais e estaduais brasileiros emitiram decretos que restringiram o acesso a diversos aspectos da cidade, impondo o uso de máscara de proteção e o isolamento e distanciamento sociais, para conter a proliferação do vírus.

Tal medo gerou uma profunda mudança no comportamento social no tocante à valorização dos espaços da cidade como principais locais de manifestação das múltiplas expressões da vida urbana; o qual, além de afetar "o encontrar-se" com pessoas, também se estendeu a "o tocar" nestas. Esse medo, também acabou afetando as relações familiares e conjugais, causando, em todos esses casos, impactos físicos e psicológicos ainda não mensurados pela ciência.

Segundo Mendes et al. (2020) o atual contexto pandêmico tende a ampliar as dificuldades enfrentadas pelas pessoas com deficiência na cidade, visto que, ao integrarem o grupo de risco da Covid-19, elas enfrentam uma série de restrições particulares, como enfrentar maior risco de vida relacionado ao aumento das barreiras à acessibilidade.

Essa ampliação decorre basicamente do já mencionado "fator medo", que se desdobra nas duas vertentes mencionadas, afunilam-se no medo de se infectar ao ser tocado ou a tocar as superfícies e estruturas edificadas dos espaços e sistemas de transporte urbanos, nos supermercados, farmácias, lojas, restaurantes, escadas e elevadores, já que, geralmente, necessitam apoiar-se em corrimãos, barras de apoio, tocar botões e campainhas, etc.

Isso sem mencionar a ampliação das barreiras de comunicação com pessoas com dificuldades cognitivas, auditivas e visuais. Cada um desses casos merece estudos mais aprofundados que demonstrem evidências dessas relações em tempos de isolamento da vida urbana.

Vale mencionar, ainda, o caso dos cadeirantes, que ficam sentados e, portanto, em uma altura inferior às pessoas em pé, estando, assim, em uma situação de maior vulnerabilidade à infecção por gotículas e aerossóis infectados. Já as pessoas com deficiência visual muitas vezes necessitam se apoiar em terceiros, tocar objetos e usar guias, e também fazer o reconhecimento dos trajetos por meio do tato.

Para além do fator de contágio, a pandemia também acabou diminuindo as atitudes solidárias para com as pessoas com deficiência, em virtude do medo de tocar o outro, o que pode gerar naquelas a sensação de abandono, insegurança, angústia e de exclusão, fazendo com que desenvolvam diversos problemas psicológicos (MENDES et al., 2020).

O quadro a seguir apresenta alguns depoimentos de quatro pessoas com deficiência que relataram, nesta pesquisa, como a pandemia da Covid-19 afetou as suas vidas cotidianas na cidade. 


\begin{tabular}{|c|c|c|}
\hline $\begin{array}{l}\text { MENOR COLABORAÇĀO } \\
\text { SOCIAL NOS } \\
\text { DESLOCAMENTOS } \\
\text { URBANOS }\end{array}$ & $\begin{array}{c}\text { PcD } 1 \\
\text { (Pessoa com Deficiência Visual) }\end{array}$ & $\begin{array}{c}\text { "Complicou demais a vida dos } \\
\text { deficientes! Antes da pandemia muita } \\
\text { gente ainda nos ajudava um pouquinho } \\
\text { nos pontos de ônibus, mas, hoje as } \\
\text { pessoas não querem mais tocar na gente } \\
\text { com medo! Mas desse jeito não tem } \\
\text { condição pra o cego ser guiadol" }\end{array}$ \\
\hline $\begin{array}{l}\text { MUDANÇA DE HABITOS } \\
\text { ESPORTIVOS E } \\
\text { ALIMENTARES }\end{array}$ & $\begin{array}{c}\text { PcD } 2 \\
\text { (Pessoa com Deficiência Física) }\end{array}$ & $\begin{array}{l}\text { "Essa pandemia mudou a minha rotina de } \\
\text { vida. Como sou paratleta de alto } \\
\text { rendimento, desde Março de } 2020 \text { ainda } \\
\text { náo voltei aos treinos, pelo medo de } \\
\text { contrair o virus e o trazer pra casa! Além } \\
\text { desse sedentarismo, isso também tem } \\
\text { afetado os meus hábitos alimentares, } \\
\text { onde tenho comido e bebido bem mais!" }\end{array}$ \\
\hline $\begin{array}{l}\text { DIFICULDADE DE } \\
\text { COMUNICAÇÃO E } \\
\text { COMPREENSÃO DAS } \\
\text { INFORMAÇŌES }\end{array}$ & $\begin{array}{c}\text { PcD } 3 \\
\text { (Pessoa com Deficiência Auditiva) }\end{array}$ & $\begin{array}{l}\text { "Sem o aparelho auditivo, me sinto } \\
\text { dificuldade de fazer a leitura labial por } \\
\text { conta da máscara que escondelfecha a } \\
\text { boca. Já com aparelho, eu consigo ouvir } \\
\text { e entender, mas depende muito da forma } \\
\text { de falar de cada pessoa." }\end{array}$ \\
\hline $\begin{array}{l}\text { DIFICULDADES DIVERSAS: } \\
\text { EDUCAÇĀO, SAÚDE E } \\
\text { FINANCEIRA }\end{array}$ & $\begin{array}{c}\text { PcD } 4 \\
\text { (Pessoa com Autismo) }\end{array}$ & $\begin{array}{c}\text { “A pandemia afetou de várias formas a } \\
\text { minha vida diária, uma delas foi a } \\
\text { suspensão do ensino presencial, que } \\
\text { fazia parte da minha rotina, o que acabou } \\
\text { por interferir no curso da minha } \\
\text { graduação. } \\
\text { Além disso, o distanciamento social em } \\
\text { si já traz consigo esse sentimento de } \\
\text { pesar, ansiedade e tristeza. Por algum } \\
\text { tempo, além de me sentir mais ansiosa, } \\
\text { ainda teve a suspensão também das } \\
\text { terapias que faço/fazia, o que acabou } \\
\text { agravando ainda mais a situação. Fora } \\
\text { isso, também houveram os impactos } \\
\text { econômicos na minha familia." }\end{array}$ \\
\hline
\end{tabular}

Quadro 1: Síntese de relatos de Pessoas com Deficiência PcDs (por tipo de deficiência). Fonte: Elaborado pelos autores. 
Esses indivíduos foram afetados pelo surto da Covid-19 de modo desproporcional ao dos demais grupos sociais, em virtude de diversos fatores, como a abrupta interrupção de tratamentos médicos e fisioterapêuticos, o que acabou expondo-os a maiores riscos de agravamento de problemas de saúde pré-existentes e/ou ao desenvolvimento de novas patologias. Além disso, com a necessidade de isolamento e distanciamento sociais houve naturalmente uma considerável diminuição do fluxo de pessoas na cidade, o que acabou diminuindo o apoio humano às pessoas com deficiência nos seus deslocamentos urbanos, sendo imposta a estas a ampliação do confinamento, do isolamento e da solidão em seus lares, afetando-lhes isso negativamente o bem-estar mental (ONU, 2020).

Para Bezerra e Cunha Júnior (2020), devido à necessidade de isolamento e distanciamento sociais, essa pandemia trouxe uma ressignificação dos espaços de socialização, e, consequentemente, maiordependência do uso do ciberespaço. Este, por sua vez, tornou-se um local onde as pessoas têm habitado cada vez mais, sendo formada uma série de territorialidades simbólicas nesses espaços virtuais.

Assim, o desinteresse pela cidade e a predominante habitação do ciberespaço pelos cidadãos da primeira fila em virtude da mixofobia apontados por Bauman (2009), agora, são substituídos pelo êxodo físico-virtual, impulsionado não mais pelo medo do outro, mas pelo medo comum da infecção e, possivelmente da morte por ela. Esse medo recentetem desencadeado novas formas de fragmentação da convivência urbana, pois, segundo Virilio (1993), existe, nesse tipo de migração física-virtual, a substituição do face a face humano e do contato urbano para a fria interface homem-máquina.

Essa habitação do ciberespaço não é algo nada novo para as pessoas com deficiência, uma vez que, antes da pandemia, já estavam, em sua maioria confinadas, em seus lares e também nos espaços virtuais, em virtude dos supracitados déficits de acessibilidade urbana presentes nas cidades brasileiras.

Portanto, nesse cenário pandêmico, ocorreram, dois fenômenos: 1) o re-confinamento desses indivíduos em seus lares, pois ainda em meio à colheita dos primeiros frutos de suas conquistas institucionais e legais tiveram que "voltar pra casa"; e, 2) a ampliação da habitação e uso do ciberespaço, o que não constitui uma ressignificação deste, pois nele já habitavam há muito tempo e lá desenvolviam a maioria das suas relações sociais.

Esse cenário de dificuldades e incertezas potencializou a representação mental negativa que as cidades contemporâneas brasileiras já inflingiam a esses indivíduos, devido às suas diversas restrições no acesso e no uso seguro de seus espaços, previamente existentes. Restrições que,são, agora, mais abstrata, mas não menos imobilizadora; impondo uma barreira pandêmica invisível, contra a qual não existe nenhuma segurança jurídica ou institucional a qual se possa recorrer. Barreira essa, mesmo que "inconscientemente", legitimada pelos poderes públicos e pela sociedade.

\section{Novo normal: determinismos vs incertezas}

O atual momento vincula-se, de certo modo, ao determinismo racional da visão modernista de cidade do período sucedido após a II Guerra Mundial. À época, 
mudanças construtivas deveriam oferecer melhores condições de acesso aos militares amputados no pós-guerra, nos EUA e Europa, onde surgiu o movimento pelo desenho universal e seus sete princípios norteadores (MACE, 1991). Devido ao fato de termos que lidar com a continuidade da implantação desses princípios, mesmo no cenário de insegurança sanitária urbana atual, colocamos algumas indagações no quadro a seguir.

Estimando que essa pandemia permanecerá ativa por mais alguns anos, causando mortes e medo, emergem novos modelos de como adequar o ambiente construído às possíveis futuras necessidades humanas, tanto em edificações como no espaço público.

Makhno (2020), por exemplo, acredita que, mesmo no período pós-pandêmico, as pessoas adotarão um estilo de vida mais reservado, preferindo espaços mais privativos e isolados do público em geral, recolhendo-se em bunkers e em edificações que tendem a ser autossuficientes energética e hidricamente. $\mathrm{O}$ autor ainda declara que grande parte desses novos espaços privativos terão como modelo o conceito de smart home, com protocolos automatizados de desinfecção da água e do ar, e que também haverá uma predominante adoção profissional do working-from-home, tendência na qual o trabalho converge para o ambiente da moradia.

Nessa mesma linha de raciocínio, Ogundehin (2020) afirma que, devido à inevitável convivência com o Coronavírus, teremos que nos proteger cada vez mais deste, cenário onde os lares se adaptarão e desempenharão um papel central nessa defesa. Para o mesmo, isso será viabilizado por meio da adoção de tecnologias de construção e de design eficientes, que ressignificarão intensamente o papel do nosso lar, o qual passará a constituir o principal locus de execução de múltiplas tarefas, outrora realizadas em outros lugares da cidade, como escritório, academia, escola etc.

No entanto, devido às incertezas que envolvem o futuro pós-pandêmico, tais projeções, não podem determinar com exatidão modelos padronizados de um "novo normal". Isso por serem incapazes de prever questões básicas, como a relativa à campanha de vacinação e tudo o que a constitui ou quanto a tratamentos eficazes contra a Covid-19, ou, ainda, o possível surgimentode novas pandemias com outras formas de contágio e de riscos à vida humana.

No cenário atual, as mudanças de padrões nas dinâmicas da vida urbana foram inseridas na sociedade em um tempo recorde, as quais abrangeram as dimensões física e virtual. No primeiro caso, houve a negação dos espaços da cidade como locais de socialização; e, no segundo, houve a ampliação da "habitação" no ciberespaço, como percebe-se com o maior tempo de permanência nas redes sociais e nas plataformas de streaming, e com o aumento de uso de plataformas de videoconferências e da Internet de forma geral.

Podemos, então, notar que, no que tange a mudança de paradigmas acerca dos espaços da cidade na situação atual, conforme exposto anteriormente, ocorre um processo de subjetivação aos moldes apontados por Agamben (2009), com o qual se constitui um novo sujeito: padrão do "novo normal", e confinado e "seguro" no seu ambiente privado, em detrimento da dessubjetivação do velho sujeito urbano. 


\begin{tabular}{|c|c|c|}
\hline PRINCÍPIOS & OBJETIVO & NOVOS DESAFIOS PóS-COVID-19 \\
\hline EQUIPARAÇÃO DE USO & $\begin{array}{l}\text { Proporcionar os mesmos } \\
\text { recursos e condições para todos }\end{array}$ & $\begin{array}{l}\text { Como garantir segurança para todas as } \\
\text { pessoas com/sem deficiência em relação ao } \\
\text { uso de equipamentos urbanos, vias de } \\
\text { circulação e meios de transporte? Como } \\
\text { dispor de dispositivos de higiene em vias } \\
\text { públicas e oferecer informaçóes sobre a } \\
\text { importância da higiene das mãos? }\end{array}$ \\
\hline FLEXIBILIDADE NO USO & $\begin{array}{l}\text { Atender a maior variedade de } \\
\text { usuários e suas capacidades e } \\
\text { habilidades }\end{array}$ & $\begin{array}{l}\text { Como ampliar o atendimento ao público de } \\
\text { PCDs, de forma segura, aos espaços } \\
\text { urbanos, controlando o potencial de } \\
\text { contaminação da covid-19, em especial às } \\
\text { pessoas com dificuldades de compreensão e } \\
\text { de comunicação da linguagem escrita? } \\
\text { Como prestar atendimento de saúde pública } \\
\text { em UBS e UPA, em linguagem acessível e } \\
\text { clara sobre os riscos da covid-19? }\end{array}$ \\
\hline USO SIMPLES E INTUITIVO & $\begin{array}{l}\text { Informações perceptíveis, baixa } \\
\text { complexidade, facilidade de } \\
\text { leitura e compreensão }\end{array}$ & $\begin{array}{c}\text { Como advertir/proteger as PCDs da } \\
\text { contaminação, por meio de informações } \\
\text { seguras, enquanto usam e se deslocam no } \\
\text { meio urbano? }\end{array}$ \\
\hline INFORMAÇÃO PERCEPTÍVEL & $\begin{array}{l}\text { Proporcionar meios diferentes e } \\
\text { variados de comunicação, } \\
\text { contraste adequado, clareza de } \\
\text { informação, recursos adicionais } \\
\text { a pessoas com limitações } \\
\text { sensoriais }\end{array}$ & $\begin{array}{l}\text { Como proporcionar que a informação sobre } \\
\text { segurança sanitária chegue a todas as } \\
\text { pessoas, com linguagens diferentes, mas } \\
\text { garantindo a facilidade de compreensão da } \\
\text { informação, em postos de saúde, meios de } \\
\text { comunicação formal, redes sociais e meios } \\
\text { de transporte, com especial atenção aos } \\
\text { locais e datas para vacinação e } \\
\text { atendimento de saúde pública? }\end{array}$ \\
\hline TOLERÂNCIA AO ERRO & $\begin{array}{l}\text { Minimizar riscos e acidentes, } \\
\text { proporcionar segurança, dar } \\
\text { alertas se necessário }\end{array}$ & $\begin{array}{l}\text { Como advertir PCDs dos riscos de } \\
\text { acidentes, em travessias, no uso de } \\
\text { transporte público, nos deslocamentos em } \\
\text { geral, sem agravar as chances de } \\
\text { contaminação de pessoas que estão } \\
\text { ajudando? }\end{array}$ \\
\hline MINIMIZAR ESFORÇO FÍSICO & $\begin{array}{c}\text { Utilizar com eficiência e } \\
\text { conforto, favorecer posturas } \\
\text { corporais neutras, pouco esforço } \\
\text { para operação, minimizar } \\
\text { repetições }\end{array}$ & $\begin{array}{l}\text { Como acelerar mecanismos legais para } \\
\text { redução das barreiras construídas urbanas, } \\
\text { que causam impedimentos de circulação } \\
\text { segura e confortável para PCDs, } \\
\text { requalificando espaços urbanos, oferecendo } \\
\text { banheiros públicos acessíveis, lavatórios } \\
\text { públicos e condições de higienização } \\
\text { adequadas, em ruas e edificações públicas? }\end{array}$ \\
\hline USO ABRANGENTE & $\begin{array}{c}\text { Proporcionar espaços e } \\
\text { dimensões apropriadas ao uso, } \\
\text { alcance visual adequado, acesso } \\
\text { e utilização confortável, sentado } \\
\text { ou em pé, acomodar variações } \\
\text { de pegas e mãos, adequar } \\
\text { espaços ao uso de órteses e } \\
\text { elementos de apoio. }\end{array}$ & $\begin{array}{c}\text { Como ampliar as condiçốes de conforto e } \\
\text { segurança no uso do espaço urbano e } \\
\text { manuseio de objetos e mobiliário urbano, } \\
\text { para que a acomodação de PCD seja efetiva } \\
\text { e apropriada a contemporaneidade e } \\
\text { igualdade social? }\end{array}$ \\
\hline
\end{tabular}

Quadro 2: Cenários e desafios para implantação dos princípios do Desenho Universal nas cidades, com a Covid-19. Fonte: Elaborado pelo autores. 
Castells (2020) possui uma visão mais otimista acerca dessa migração rumo ao ciberespaço, o teórico acredita que estamos entrando totalmente em uma sociedade digital na qual já vivíamos, embora ainda não tivéssemos assumido. Também sugere que esse movimento é progressivo, e defende a ideia de que a completa digitalização da nossa organização sócioeconômica se tornará uma estrutura social permanente, para a manutenção da nossa comunicação em todas as circunstâncias, sendo aquela a base das nossas formas de viver em sociedade. Contudo, Castells (2020) ainda sustenta que o mundo será necessariamente híbrido, composto pelas realidades mundana e digital, convergindo em uma cultura de virtualidade real, na qual a virtualidade nada mais será do que uma projeção da nossa realidade, para a qual, neste momento pandêmico, podemos nos retirar, recomeçar e adaptar.

Já para Agamben et al. (2020), como no campo religioso, a ciência também pode produzir e disseminar superstições e novos comportamentos, e que, nessa perspectiva os meios de comunicação, os poderes públicos têm se empenhado na disseminação de um clima de pânico na sociedade. Esse uso indevido gera um verdadeiro estado de exceção que impõe severas restrições à vida urbana, onde existe uma forte tendência de normalizá-lo como paradigma de governo, o que notoriamente fere as liberdades individuais dos cidadãos.

Segundo o mesmo, tal estado de medo e pânico coletivos tem sido inconscientemente internalizado pelos indivíduos, os quais passam a aceitar tais restrições por assumirem a forma de proteção estatal contra a infecção, onde os governos se apresentam como garantidores dessa proteção. Como para Agamben (2009, p. 40-46) o dispositivo é:

"[...] qualquer coisa que tenha de algum modo a capacidade de capturar, orientar, determinar, interceptar, modelar, controlar e assegurar os gestos, as condutas, as opiniões e os discursos dos seres viventes." e, que este constitui, antes de tudo, "[...] uma máquina que produz subjetivações e somente enquanto tal é também uma máquina de governo" (AGAMBEN, 2009, p. 40-46).

Podemos, então, inferir que, embora a pandemia de Covid-19 constitua um real problema sanitário e demande uma série de cuidados, também se configura como um dispositivo de governo que se dispõe a gerar uma nova ordem social, a qual se estabelece por meio de diversos processos de subjetivação, e na qual também se cria um novo homem-padrão em detrimento do velho sujeito urbano.

Essas metanarrativas acerca de um inevitável padrão de novo normal remontam ao Modernismo Universal (ou Alto) do período pós II Guerra Mundial que, segundo Harvey (2008), possuía uma visão positivista e tecnocrática, que acreditava em um progresso linear, em verdades absolutas e defendia a ideia de planejamento racional de ordens sociais ideais. Isso sob condições padronizadas de conhecimento, que, na arquitetura e planejamento urbano desse período, se personificava no desprezo à personalização e à subjetividade, posto que as soluções gerais de cidade prevaleciam sobre o atendimento das necessidades individuais dos cidadãos. Perspectiva essa que, segundo o mesmo autor, foi superada a partir do início da década de $1970 \mathrm{com}$ a perspectiva pós-moderna de cidade, e de outras subsequentes, onde se passou a considerar o construir para as pessoas, e não para o homem.

Essa crítica aos discursos gerais e deterministas pode, ainda, ser encontrada em Morin (2020) que declara que todas as futurologias do século XX que se aventuraram 
a tentar prever o futuro, embasadas nas correntes que atravessaram o presente, fracassaram; destacando que apesar disso, ainda há tentativas de prever 2025, 2050..., mesmo com a incapacidade de se compreender o hoje. O mesmo acredita que, neste cenário pandêmico, não temos como saber se devemos esperar o pior, o melhor ou ambos, pois caminhamos rumo a novas incertezas - embora certas teorias aceitas tendam a se tornarem dogmáticas nas cúpulas acadêmicas - mesmo que a incerteza não permita saber se ao menos após esse atual confinamento a ordem abalada será ou não restabelecida.

Em face do exposto, entendemos que, embora a atual fase pandêmica tenha sido um cenário fertil para a emergência de diversos discursos deterministas, que desencadearam um sentimento geral de medo e de negação dos espaços da cidade (como principais locais da manifestação da vida urbana e da sociabilidade), ainda não possuímos indícios suficientes para determinarmos com razoável grau de assertividade um padrão de "novo normal", ou seja, de que a vida nas cidades será de fato desta ou daquela maneira.

Agamben (2009, p, 64) considera contemporâneo: "[...] quem não se deixa cegar pelas luzes do século e consegue entrever nessas a parte da sombra, a sua íntima obscuridade.". Então, baseados na afirmação desse autor, resta o desafio de não deixar cegar-se por essas "luzes" ou "certezas" tão presentes nos discursos dominantes acerca do que virá a ser o amanhã pós-pandêmico nas cidades.

Retomando o foco do debate aqui proposto, questiona-se: onde as pessoas com deficiência estarão inseridas no futuro pós-pandêmico das cidades brasileiras? Ainda não se sabe, mas é esperado que não mais confinadas em suas casas e/ou no ciberespaço, mas tendo autonomia plena para transitarem livremente em quaisquer tipos de espaços, sejam físicos ou virtuais, e para, assim, desenvolverem sem barreira alguma as suas potencialidades em espaços de esperança, liberdade e inclusão, e não em espaços de reconfinamento.

\section{CONSIDERAÇõES FINAIS}

Este trabalho expôs como a celebração da valorização dos espaços públicos, como principais locais da efetivação da vida urbana nas suas mais diversas e ricas manifestações, têm sofrido profundas modificações em virtude da pandemia do coronavírus. Espaços esses que, "da noite para o dia", passaram de imprescindíveis à vida urbana plena para locais de infecção e respectiva morte, de desejáveis a inadequados, o que acabou ampliando o rol de barreiras à acessibilidade para algo bem mais abstrato do que as clássicas barreiras convencionais enfrentadas pelas pessoas com deficiência em suas "aventuras" pela cidade.

Buscou-se nesste trabalho também descrever como a pessoa com deficiência esteve, está e espera-se que esteja inserida na vida urbana das cidades brasileiras antes e após a supracitada pandemia. Apresentou-se ainda o pensamento clássico de valorização dos espaços públicos da cidade em autores como Bauman (2009), Lefebvre (2001), Jacobs (2011) e Gehl (2015), contrapondo-o com a cidade real vivenciada pelas pessoas com deficiência, onde os excludentes desenhos urbanos dessa acabam impondo a tais indivíduos o confinamento em casa e/ou no espaço virtual. 
Em seguida, tratou-se de como o medo dos espaços urbanos como locais de infecção pela Covid-19 mudou a ideia de valorização dos tais. Situação esta que acabou ampliando as barreiras à acessibilidade para algo mais abstrato e psicologicamente danoso como o medo do outro como transmissor do vírus; o que, ao seu turno, gerou tanto o reconfinamento como a ampliação do confinamento já amplamente vivenciado pelas pessoas com deficiência. Neste contexto, surge a barreira pandêmica à acessibilidade, contra a qual não existem dispositivos legais aos quais se possa recorrer para que se garanta o ir e vir desses indivíduos.

Por último, realizou-se uma crítica aos atuais discursos hegemônicos acerca de um inevitável padrão de "novo normal" para o futuro das cidades e modos de interação humana nelas desenvolvidos, teoricamente apoiada por Agamben (2009; 2020) e Morin (2020).

Diante de tudo isso, é possível concluir que, ao longo da história do desenvolvimento das cidades, as pessoas com deficiência foram geralmente desconsideradas, restando às mesmas o confinamento em seus lares. Mais recentemente, com o advento da pandemia da Covid-19, houve a ampliação do conceito de barreiras à acessibilidade, agora para algo mais abstrato, como o medo da infecção e da consequente morte. Barreira nova esta contra o qual não existe proteção jurídica, institucional ou social, que gerou tanto o reconfinamento como a ampliação do confinamento desses indivíduos, restando-lhes como alternativa "o mover-se" no ciberespaço.

No que diz respeito ao futuro pós-pandêmico das cidades, dos modos de vida e de interação social que virão a ser desenvolvidos nelas, resta a esperança de que as cidades brasileiras garantam o pleno desenvolvimento e suas potencialidades a esses cidadãos, o que só pode acontecer quando Ihes for garantida a possibilidade de autonomia, conforto e segurança em seus deslocamentos físicos e/ou virtuais.

\section{REFERÊNCIAS}

AGAMBEN, G. O que é contemporâneo? e outros ensaios. Tradução Vinícius Nicastro Honesko. Chapecó: Argos, 2009.

AGAMBEN, G. et al. Sopa de wuhan: pensamiento contemporaneo en tiempos de pandemias. Buenos Aires: ASPO, 2020. Disponível em: https://www.medionegro. org/pdf-sopa-de-wuhan/. Acesso em: 12 jan. 2021.

BAUMAN, Z. Confiança e medo na cidade. Tradução Eliana Aguiar. Rio de Janeiro: Zahar, 2009.

BEZERRA, M. A.; CUNHA Jr., M. F. Cidades, espaços públicos e comportamento: discussões sobre o cenário urbano no contexto de pandemia global. Observatório das Metrópoles, 2020. Disponível em: https://www.observatorio dasmetropoles.net.br/cidades-espacos-publicos-e-comportamentodiscussoes-sobre-o-cenario-urbano-no-contexto-de-pandemia-global/. Acesso em: 16 set. 2020. 
CASTELLS, M. O digital é o novo normal. Fronteiras do Pensamento, 26 maio. 2020. Disponível em: https://www.fronteiras.com/artigos/o-digital-e-o-novo-normal. Acesso em: 18 set. 2020.

GARCIA, C. C. Sociologia da acessibilidade. Curitiba: IESDE, 2012.

GEHL, J. Cidades para pessoas. Tradução Anita Di Marco. 3. ed. São Paulo: Perspectiva, 2015.

HARVEY, D. Condição pós-moderna: uma pesquisa sobre as origens da mudança cultural. Tradução Adail Ubirajara Sobral e Maria Stela Gonçalves. 17. ed. São Paulo: Edições Loyola, 2008.

JACOBS, J. Morte e vida de grandes cidades. Tradução Carlos S. Mendes Rosa. 3. ed. São Paulo: WMF Martins Fontes, 2011.

LEFEBVRE, H. O direito à cidade. Tradução Rubens Eduardo Frias. São Paulo: Centauro, 2001.

MACE, R. et al. Accessible environments toward Universal Design. In: PREISER, W.; VISCHER, J. C.; WHITE, E. T. (eds.). Design interventions: toward a more humane architecture. Nova lorque: Van Nostrand Reinhold, 1991.

MAKHNO, S. Life after coronavirus: how will the pandemic affect our homes? Dezeen, 25 mar. 2020. Disponível em: https://www.dezeen.com/2020/03/25/life-aftercoronavirus-impact-homes-design-architecture/. Acesso em: 16 set. 2020.

MARICATO, E. Para entender a crise urbana. São Paulo: Expressão Popular, 2015.

MENDES, A. et al. (orgs.). Diálogos sobre acessibilidade, inclusão e distanciamento social: territórios existenciais na pandemia. Rio de Janeiro: Fiocruz; IdeiaSUS; ENSP; UFG, 2020. 61 p.

MORIN, E. Um festival de incerteza. Gallimard, 21 abr. 2020. Disponível em: http://www. ihu.unisinos.br/78-noticias/599773-um-festival-de-incerteza-artigo-de-edgarmorin. Acesso em: 18 set. 2020.

OGUNDEHIN, M. In the future home, form will follow infection. Dezeen, 4 jun. 2020. Disponivel em: https://www.dezeen.com/2020/06/04/future-home-formfollows-infection-coronavirus-michelle-ogundehin/. Acesso em: 16 set. 2020.

ORGANIZAÇÃO DAS NAÇÕES UNIDAS. Global forum on the covid-19 crisis and persons with disabilities. Disponível em: https://www.un.org/development/desa/ disabilities/news/news/global-forum-covid-19.html. Acesso em: 15 set. 2020.

VIRILIO, P. O espaço crítico. Tradução Paulo Roberto Pires. Rio de Janeiro: Editora 34, 1993. 